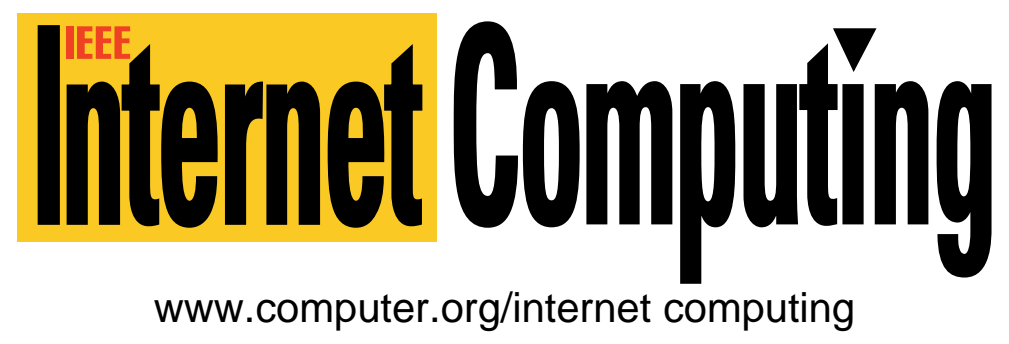

\title{
Ten Ideas for Policymakers to Drive Digital Progress
}

\author{
Daniel Castro and Rob Atkinson
}

Vol. 13, No. 2

March/April 2009

This material is presented to ensure timely dissemination of scholarly and technical work. Copyright and all rights therein are retained by authors or by other copyright holders. All persons copying this information are expected to adhere to the terms and constraints invoked by each author's copyright. In most cases, these works may not be reposted without the explicit permission of the copyright holder.

\section{IEEE (D) computer society}

(c) 2009 IEEE. Personal use of this material is permitted. However, permission to reprint/republish this material for advertising or promotional purposes or for creating new collective works for resale or redistribution to servers or lists, or to reuse any copyrighted component of this work in other works must be obtained from the IEEE. 


\title{
Ten Ideas for Policymakers to Drive Digital Progress
}

Daniel Castro and Rob Atkinson • Information Technology and Innovation Foundation

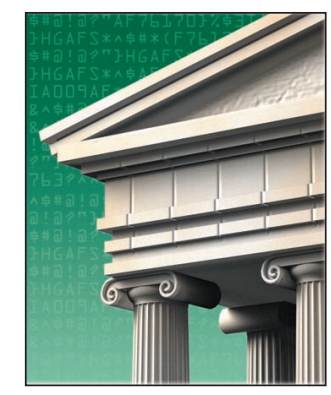

\begin{abstract}
Innovators continue to find new ways to use information technology (IT) to make our lives better. Looking forward, IT will continue to be a critical component of solutions to many social challenges. But policymakers must create the right environment for technological progress. This article offers 10 guiding principals for creating technology policy that spurs and sustains digital progress.
\end{abstract}

I n 2008, the Information Technology and Innovation Foundation (ITIF) released the report "Digital Quality of Life: Understanding the Personal and Social Benefits of the Information Technology Revolution," which shows how information technology (IT) is the key enabler of many, if not most, of the major innovations and improvements in our lives and society. The report explores how today's IT is transforming virtually every area of life for individuals and society - from education and healthcare to energy and public safety. Many of these transformations will be familiar to casual technology observers, such as the increase in telework and online learning, whereas other changes have only appeared in the past few years, such as rapid-learning health networks and intelligent transportation systems. Perhaps what is most revealing isn't the impact of any particular technology or innovation but rather the combined effect of all this technology on our daily lives.

Although the report avoids idealizing technology or resorting to lofty rhetoric to describe technological progress, neither does it shy away from the conclusion that IT is rapidly moving us to a more intelligent and connected world. The continued advancement of IT has created a world of low-cost sensors, processors, and data storage devices that make it easy to collect, store, and process vast quantities of digital information. In addition, high-speed broadband networks have created global information flows that let users send data effortlessly almost anywhere in the world with only a few keystrokes.

Unfortunately, policymakers too often ignore IT's important role in improving our world. In fact, addressing almost every major social challenge we face today - from using electronic health records to control healthcare's rising costs to investing in the smart grid to create a less carbon-intensive economy - will require public policymakers to implement IT solutions. Drawing on success stories around the globe, we've developed 10 key principles that policymakers should follow to maximize IT's potential benefit for their citizens and society.

\section{Use Digital Progress \\ to Improve Quality of Life}

IT provides many prospects for improving communities, but policymakers must recognize these opportunities to take advantage of them and improve general quality of life. Consider the massive transportation challenges facing leaders at all government levels. Growing populations and higher levels of personal vehicle ownership worldwide mean more cars and trucks are on the road than ever. Consequently, communities face problems such as traffic congestion, insufficient parking, and increased pollution. For example, transportation causes approximately one-quarter of the $\mathrm{CO} 2$ emissions in the UK. ${ }^{1}$

IT is enabling many solutions to address these challenges. For example, the availability of low-cost, on-vehicle transponders lets coun- 
tries such as the Netherlands and Sweden implement electronic roadpricing programs to more closely align vehicle taxes and fees with usage. Fees can be charged based on total vehicle miles traveled or time of use, thereby letting government transportation officials use pricing mechanisms to reduce traffic congestion. After Singapore implemented an electronic road-pricing program, morning traffic volume dropped by 45 percent as commuters opted for other forms of transportation (www. economic-policy.org/pdfs/Santos _final.pdf). IT is even making parking easier in places such as San Francisco, where 6,000 wireless sensors will be installed to help drivers locate vacant parking spots. And, sensors to detect traffic patterns or road-weather conditions to receiving GPS data for computer-assisted navigation. Road operators can then harness this data to better manage traffic flows, improve traffic-signal timing, and enhance road safety.

\section{Invest in Digital Progress}

Investing in digital progress pays significant dividends to individuals and society because most of this technology has multiple uses. Governments in particular should invest - the private sector often tends to underinvest in IT because it can't always capture the full benefit of its investment. To take just one example, consider how the IT revolution has impacted people with disabili-

\section{IT provides many prospects for improving communities, but policymakers must recognize these opportunities to take advantage of them and improve general quality of life.}

of course, high-speed broadband networks let increasing numbers of commuters avoid the roads altogether by simply working from home. In the US in 2007, telecommuters saved 840 million gallons of gasoline and reduced carbon emissions by almost 14 million tons (www.techceocouncil. org/images/stories/pdfs/TCCsmart green2-1.pdf).

In addition, as vehicles become smarter, they often become safer. The next wave of IT-based vehicle safety features could improve on existing options such as adaptive cruise control and electronic stability control to offer advanced collision warning and avoidance systems. And, increasingly, vehicles are becoming another node in the global flow of information by both sending and receiving data - from acting as ties. The shift from an analog to a digital world has made it easier for users to choose the medium in which they receive information, be it voice, text, or even physical patterns (for example, Braille). Whereas 20 years ago, only a paper copy of the New York Times was available, today we can enjoy it in print, online, or even on mobile devices. Visuallyimpaired readers can use text-tovoice technology to hear articles and subscribe to podcasts from leading columnists. Moreover, advances in IT let those with disabilities better meet their needs with multipurpose technology. For example, speech-recognition software enables individuals with mobility impairments to control a computer with their voices, and cell phones with texting and instant messaging capabilities let indi- viduals with hearing disabilities use mobile communication.

Although private businesses and individuals will develop and pay for much of this technology, government support for research and development can accelerate progress through federal labs, joint publicprivate partnerships, and assistance to private sector efforts. In addition, government can invest in IT applications designed specifically for core public functions, such as government services, transportation, healthcare, public safety, and the environment. This investment can come in multiple forms, including direct public investment, tax credits, and loan guarantees. And during downturns in the economy, policymakers should develop stimulus proposals to invest in IT, not only to create more jobs in the short-term, but also to support long-term economic growth and other societal benefits.

\section{Ensure Affordable and Widespread Digital Infrastructure}

Certain key technologies that make up the digital infrastructure behind many of the improvements in our quality of life need additional government investment. This means that government shouldn't just spur investment in the foundations of our digital society, such as high-speed broadband Internet, but should also work to ensure that progress continues in other areas. This means taking measures such as opening up unused "white spaces" to ensure adequate spectrum is available for wireless innovation and continuing to develop ever more precise GPS signals.

One example of the need for a larger public policy role is with the intelligent power grid, or smart grid. ${ }^{2}$ The smart grid is intended to be a revolutionary network, much like the Internet, that will deliver power more efficiently and reliably than our existing power grid. Us- 
ing the smart grid, utilities can access real-time data from sensors and advanced meters distributed throughout the power grid to better understand specific supply and demand requirements, spot failed or failing equipment, and better manage their resources. The smart grid will enable a host of societal benefits, including lowering peak demand and its associated costs, enabling the greater use of clean energy, and providing electricity more reliably. Moreover, the smart grid will facilitate the seamless integration of new technologies, including "smart" appliances that respond to dynamic price signals, plug-in hybrid electric vehicles, distributed generation (for example, residential solar panels), and energy storage solutions. However, policymakers must work to ensure that public policy supports this vision by, for example, decoupling utility profits from energy sales and instead creating an incentive structure that lets utilities profit from energy efficiency.

\section{Encourage Widespread Digital Literacy}

Not only do policymakers need to ensure that we have a robust digital infrastructure, they must also work to ensure computer literacy and provide the IT tools necessary to participate in a digital world. Although communities worldwide face this challenge, developing nations in particular must address this issue head on. In some countries, efforts to bring about digital literacy and technology adoption take a backseat to more pressing humanitarian needs, such as widespread poverty, malnutrition, and other health crises. IT alone can't solve all these problems, but it can play an important role in addressing many of these challenges in developing nations.

For example, the Kenyan healthcare system faces a shortage of skilled nurses to treat critical dis- eases such as HIV/AIDS, malaria, and tuberculosis. A shortage of instructors and training facilities meant only a few hundred nurses could be trained each year, but by implementing a computer-based training module, Kenya has begun a program to train 22,000 nurses in five years. We can see similar progress in Brazil, where they use IT to increase access to education - thousands of students now attend school via satellite links in certain rural areas where a lack of service would otherwise prevent these children from attending classes. Computer ownership lags in many countries, but cell phone ownership is much higher - as a result, a wide range of innovative applications for mobile phones, such as text-messaging applications that remind patients to take their prescriptions, are being developed for citizens in developing nations. And economists have found that access to mobile phones leads to more efficient markets - in a fish market in southern India, for example, sellers with access to mobile phones have increased their profits by 8 percent and saved consumers 4 percent. $^{3}$

\section{Overcome Obstacles to Digital Progress}

Although technological change brings many benefits, it also involves change and risk - we can't let concerns about potential or hypothetical harms derail or slow digital progress. Policymakers must address concerns about privacy, security, civil liberties, and other challenges, but the focus must remain on advancing quality of life. Consider healthcare - multiple studies have found that implementing electronic health records (EHRs) leads to lower healthcare costs and better patient outcomes. ${ }^{4}$ An EHR contains a patient's complete medical history, including full documentation on past illnesses, laboratory tests, treatments, drugs, and allergies. Patients benefit from better care and fewer medical errors when healthcare providers can link these digital records with clinical decision-support systems, such as automated diagnostic programs and drug-management systems. For example, using EHRs could eliminate roughly 200,000 adverse drug events, saving US $\$ 1$ billion annually (www.rand.org/pubs/research _briefs/RB9136/RAND_RB9136.pdf).

Unfortunately, privacy advocates in several countries have actively opposed certain efforts to adopt EHRs. Although governments must always respect and protect the rights of citizens, this debate often unfairly targets digital health information but doesn't address its paper-based counterpart. In the UK, progress on deploying electronic health records nationally had been delayed over concerns that every patient should be required to first give consent to their medical information appearing in digital form. Requiring every patient to give consent would be an unnecessarily burdensome requirement that would stifle the benefits of using EHRs that come from scale. For example, ubiquitous EHRs have the potential to revolutionize medical research by enabling technologies such as rapid-learning health networks that can derive new clinical evidence from this electronic data. EHRs could help researchers to more quickly spot dangerous side effects in a drug or identify a successful medical intervention. To address the challenge that privacy advocates pose in the UK, their National Health Service found a solid middle ground and approved a measure to presume consent for patients to have an electronic health record and still offer patients the option to opt out. This type of policy balances individual rights with protecting the public good. ${ }^{5}$

\section{Use IT to Find New Solutions to Old Problems}

Policymakers should recognize that 
IT is a means and not an end - it's unreasonable to expect that simply using IT to perpetuate existing ana$\log$ processes will lead to better solutions. Existing problems shouldn't just be digitized; IT should be used to find new solutions to old problems. Individuals can capitalize on IT's ability to collect, manipulate, and distribute data to develop innovative solutions not possible without today's technology. Consider education - researchers have debated the value of instructional technology in classrooms. In 2007, the US Department of Education released a report that found no statistically significant difference between the performance of students in classrooms using 16 different reading and math software products and students in conventional classroom environments (http:// ies.ed.gov/ncee/pdf/20074005.pdf). However, it turns out that the students in the study on average used the computers for only roughly 15 minutes per day. Because the majority of their instruction came from traditional instructional techniques, it's little wonder that there was no deviation in learning outcomes.

The larger issue is that not all educational software is created equal. In fact, you can make a clear distinction between "Type I" educational technologies that mimic the traditional teaching activities a student and teacher might engage in and "Type II" educational technologies that let educators teach using innovative new methods made possible by IT. For example, a Type I software program might be easier, cheaper, or more entertaining for students, but if it teaches using the same methods, educators shouldn't expect a significantly different learning outcome. However, a Type II software program, such as the Cognitive Tutor program developed at Carnegie Mellon University (www.carnegiemellontoday.com/ article.asp?Aid=120), can use IT to create a customized learning experience tailored to each student's learning style. In fact, using IT lets students customize the learning process, from receiving instant feedback on their progress to flexible online classes that give more people access to education than was possible before the Internet. The result is that the effectiveness of any particular IT application will depend on the implementation, curriculum, and teacher's pedagogical approach. ${ }^{6}$

\section{Create Reusable Digital Content and Applications}

Although the fixed costs of producing data or an application might be high, one of digital information's benefits is that the marginal cost of creating an additional copy is typically minimal. Creating digital data using interoperable standards, such as sharable and reusable XML, multiplies its value many times - this can be far more valuable than just building a Web site or an application that solves a single problem. For example, in Fairfax County, Virginia, local leaders are working to develop a comprehensive online database of geographic information system (GIS) data of everything in the county, from bus routes to private drinking wells. In Portland, Oregon, the city police department makes crime data available online, and in Kansas, the state Highway Patrol publishes logs of all injury and fatality crashes on its Web site to streamline the process of recording and distributing crash information to the media and the public.

The potential benefits of making much more data accessible and reusable are huge. For example, consider public safety. The US has more than 2 million miles of onshore oil and natural-gas pipelines, operated by roughly 3,000 companies. Unmapped pipelines can cause significant financial and health risks to construction crews or others who might unknowingly dig into them. But communities can create online GIS databases of these underground hazards and utility pipelines to create digital pipeline maps. Because digital images are produced and updated to the maps in real time, these maps are far more accurate and efficient than their paper ancestors. In the near future, as local governments and utility companies amass more GIS data on underground pipes and cabling, workers will be able to use GPS-enabled equipment to avoid potential hazards.

\section{Collaborate and Partner with the Private and Non-Profit Sectors}

Policymakers must recognize that government can't provide every digital solution, and sometimes government won't design the best solution. For this reason, government should embrace opportunities to partner with private and non-profit sectors. For example, to overcome language barriers to digital literacy, a coalition of governments and universities in Asia are working on the PAN Localization Project (www.panl10n. net) to develop local language digital content. In Ontario, Canada, the government has funded the development of AlphaRoute (www.alpha route.org), an online learning environment to boost adult literacy. The AlphaRoute program supplements online courses with discussion boards, live chats, and email to foster interaction between students, instructors, and mentors, and it includes special guidance for deaf students who can access online video to learn American Sign Language. In the US, the Urban Institute's National Neighborhood Indicators Partnership (NNIP; www2.urban.org/nnip) is working with city governments to develop neighborhood information systems to monitor the state of their communities by, for example, letting local leaders compare the ef- 
fectiveness of different strategies for programs such as welfare reform and prisoner reentry. All these programs recognize the importance of developing strong partnerships with nongovernment actors to achieve policy goals.

\section{Lead by Example}

Even as government partners with the private and nonprofit sectors, it should be practical and at the forefront of adopting new technology; government shouldn't rely on the private sector to be the primary market for innovative technology. Government can play an important role in spurring markets and proving concepts, and it can use its substantial purchasing power to advance technological goals, such as creating better information security in software or more energyefficient hardware.

Government leaders can create substantial benefits when they use IT to innovate. Consider the use of IT in law enforcement, such as the CompStat program, pioneered in the New York Police Department, which lets police departments use IT to more easily collect and report crime data (www.nyc.gov/html/nypd/html/ crime_prevention/crime_statistics. shtml). By applying sophisticated spatial statistics analytics to the data, police can identify high-crime areas and conduct geographicprofiling to target serial offenders. In addition, departments often make this crime data available to the public to increase public oversight and accountability. Other results are evident across the US. In Philadelphia, city officials launched a pilot program to put RFID tags in recycling bins so that they can automatically track recycling rates and reward participation with coupons redeemable at local businesses - as a result, participation rates have shot up to 90 percent. Even the US Library of Congress, rather than just build its own online photo sharing service, partnered with Flickr to establish an online photo archive that integrates Web 2.0 features to make its services more accessible.

\section{Nudge Digital}

In their recent book, Richard Thaler and Cass Sunstein describe how using "choice architecture" institutions can encourage or discourage certain group behaviors. ${ }^{7}$ Policymakers should heed this lesson and, when appropriate, implement policies that nudge citizens to adopt digital technologies that deliver proven value. For example, imagine the savings in energy and paper if, by default, all consumers received credit-card and personal banking statements electronically unless they specifically opt-in to receive paper ones. Or the similar benefits in energy savings and increased productivity if government agencies made telework the default work environment for a variety of government jobs. Many governments have recognized the value of such policies and are acting accordingly. For example, the transit authority for the subway and bus systems in Washington, D.C., recently phased in new discounts for riders who pay with a smart card to provide an incentive for riders to switch to the lower-cost electronic system. ${ }^{8}$

A lthough some have questioned whether IT still matters, the evidence is clear that not only does IT have a significant impact on our quality of life, but it will continue to have a major impact on many social and policy challenges in the future. We need to pay attention to the lessons learned in communities that have successfully embraced the IT revolution because it seems likely that progress in many areas will be determined by how well we develop and deploy IT.

\section{References}

1. P. Callaghan and J. Goodman, "ICT as a Mode of Transport," Forum for the Future, London, Dec. 2006; www.forumfor thefuture.org.uk/node/392.

2. R. Atkinson, D. Castro, and S. Ezell, The Digital Road to Recovery: A Stimulus Plan to Create Jobs, Boost Productivity and Revitalize America, special report, Information Technology and Innovation Foundation, Washington, D.C., 2009.

3. T. Arango, "Market Data, Far from the Market," New York Times, 19 Jun., 2008; www.nytimes.com/2008/06/29/business/ 29essay.html? partner=rssyahoo\&temc $=$ rss.

4. D. Castro, Improving Health Care: Why a Dose of IT May Be Just What the Doctor Ordered, special report, Information Technology and Innovation Foundation, Washington, D.C., 2007; www.itif.org/ files/HealthIT.pdf.

5. N. Timmins, "Electronic Medical Records a Step Closer" Financial Times, Sept. 2008; www.ft.com/cms/s/0/ff2823e8-85d0 -11dd-a1ac-0000779fd18c.html.

6. T. Bielefeldt, "Computers and Student Learning: Interpreting the Multivariate Analysis of PISA 2000," J. Research on Technology in Education, vol. 37, no. 4, 2005, p. 344.

7. R. Thaler and C. Sunstein, Nudge: Improving Decisions About Health, Wealth and Happiness, Yale University Press, 2008.

8. L.H. Sun, "Metro to Balance Transfer Fees for SmarTrip Users," Washington Post, Nov. 2008, p. B:1.

Daniel Castro is a senior analyst at the Information Technology and Innovation Foundation (ITIF). His research interests include technology policy, security, and privacy. Castro has an MS in information security technology and management from Carnegie Mellon University. Contact him at dcastro@itif.org.

Rob Atkinson is president of ITIF. His research interests include technology and innovation policy and growth economics. Atkinson has a PhD in city and regional planning from the University of North Carolina at Chapel Hill. Contact him at ratkinson@itif.org. 